\title{
Humidity Control Ability of Silica with Bimodal Pore Structures Prepared from Water Glass
}

\author{
Yumiko TOMITA, Ryoji TAKAHASHI, Satoshi SATO, Toshiaki SODESAWA and Makoto OTSUDA \\ Department of Applied Chemistry, Faculty of Engineering, Chiba University, 1-33, Yayoi-cho, Inage-ku, Chiba-shi 263-8522
}

\author{
水ガラスから作製した二元細孔シリカの調湿特性 \\ 冨田由美子・高橋亮治 $\cdot$ 佐藤智司 $\cdot$ 袖澤利昭 $\cdot$ 乙田 真 \\ 千葉大学工学部共生応用化学科, 263-8522 千葉市稲毛区弥生町 1-33
}

\begin{abstract}
Humidity control ability of monolithic bimodal porous silica gel prepared from water glass in the presence of poly (acrylic acid) was investigated from the viewpoints of both equilibrium and kinetic aspects. The humidity, at which adsorption-release of water vapor occurred reversibly, was systematically controlled by changing the mesopore size. The equilibrium adsorption amount of water was as high as $0.7 \mathrm{~g}$ per gram of silica. In addition, the presence of macropores made it possible to quickly response for humidity change by the adsorption-release cycle because of rapid gas diffusion in monolithic gel body. These features are quite attractive as a material for humidity control in the airtight buildings.

[Received April 28, 2004; Accepted July 30, 2004]
\end{abstract}

Key-words : Humidity control, Bimodal pore structure, Rapid diffusion, Silica gel, Water glass

\section{Introduction}

High-level air-tightness and thermal insulation have been required to recent buildings and houses from the demands of comfortable life space and saving energy. In such buildings, ventilation and humidity control are necessary to avoid various troubles, such as sick-building syndrome, unusual dry-air, dew condensation, and growth of mold. These have been achieved by the use of electric appliances such as air-conditioner and steamer. On the other hand, uses of porous materials, which are absorbable of water vapor, attract much attention for the energy-less humidity control. ${ }^{1-7)}$ In the purpose, a material, which can adsorb water vapor at high humidity and can release at low humidity, is required to maintain the humidity in the building at an appropriate level. In mesopores with radius of $r_{\mathrm{p}}$, vapor condenses in pores over the appropriate relative pressure, $P / P_{0}$, by capillary condensation. ${ }^{8)}$ This relation is approximately given by the Kelvin equation,

$$
\ln \frac{P}{P_{0}}=-\frac{2 \gamma V_{\mathrm{L}} \cos \theta}{r_{\mathrm{p}} R T}
$$

where $\gamma, V_{\mathrm{L}}, \theta, R$ and $T$ are surface tension, molecular volume of liquid, contact angle, gas constant and temperature, respectively. The relation suggests that precise control of pore size makes it possible to design adsorption-release cycles of water vapors at an appropriate humidity, because humidity is percentage explanation of $P / P_{0}$. For example, pores with diameter of ca. $5 \mathrm{~nm}$ are expected to adsorb and release water vapor over and below humidity of $65 \%$ at $20^{\circ} \mathrm{C}$ by using $\gamma=$ $0.0728 \mathrm{~N} \mathrm{~m}^{-1}$ and $\theta=0^{\circ}$. Various porous materials, such as activated carbon, silica gel, alumina gel, sepiolite and diatomite, were tested as a humidity control material. ${ }^{1-7)}$ However, most of them are obtained as small grains or powders, and molding to be a board or a tile is required for the use as building materials. ${ }^{1), 7)}$

On the other hand, a monolithic silica gel with bimodal pores has been prepared by the sol-gel process. ${ }^{9-11)}$ In the silica, macropores are formed by freezing a transitional structure of phase separation, and their size is controllable by changing the preparation conditions such as reaction temperature and compositions. ${ }^{11)}$ The size of mesopores reflecting the aggregation structure of primary silica particles is also controllable by aging in a basic solution. ${ }^{12)}{ }^{13}$ ) In the bimodal porous silica, mesopores act as functional surfaces after surface modification, and macropores serve high-speed pathway to gas- and liquid-phases molecules to reach the surface in mesopores. Because of this advantage in the bimodal porous silica gel, it has high potential in many applications where both molecular transportation and surface interaction concur. ${ }^{14)-19)}$ Considering to apply the silica as a humidity control material in a monolithic form, it would be the most suitable because the macropores would work to promote the gas transportation within a monolithic body whereas we can control the mesopore size in order to adsorb water vapor at an appropriate humidity. Because of high cost of silicon alkoxide as a raw material, however, it was difficult to use the bimodal porous silica as building materials.

We recently succeeded in preparing the bimodal porous silica from water glass, an industrial raw material of silica gel. ${ }^{20), 21)}$ Then, its application as a humidity control material becomes quite interesting. In this work, we prepared the bimodal porous silica gel from water glass with controlled mesopores, and investigated its humidity control ability from the viewpoints of both equilibrium and kinetic aspects.

\subsection{Sample preparation}

\section{Experimental}

Bimodal porous silica gels were prepared from water glass (JIS No. 3 water glass containing 29 mass $\% \mathrm{SiO}_{2}$ and 10 mass $\% \mathrm{Na}_{2} \mathrm{O}$, Tokuyama Co.) according to the method reported previously. ${ }^{20)}$ Poly (acrylic acid) (HPAA) with an average molecular weight of 25000 (Wako Pure Chemicals Co.) was used to induce phase separation. Starting compositions were water glass: water: $\mathrm{HNO}_{3}$ (60 mass \% aqueous solution): HPAA $=50: 97: 37: 6.5$ in weight ratio. Firstly, powder reagent of HPAA was dissolved in distilled water in a polypropylene beaker. The HPAA solution was diluted with conc. $\mathrm{HNO}_{3}$. At the same time, water glass was diluted with distilled water in another polypropylene beaker. Then, the 
water glass solution was added slowly into the acidic HPAA solution with vigorous stirring to obtain a homogeneous solution. After stirring for $10 \mathrm{~min}$, the solution was sealed in a polystyrene container, and kept at $25^{\circ} \mathrm{C}$ for $24 \mathrm{~h}$ for gelation. The obtained gel was soaked in distilled water for $3 \mathrm{~d}$ in order to remove sodium salt, and then the gel was aged in $1 \mathrm{~mol}$ $\mathrm{dm}^{-3}$ aqueous solution with either of the following solutes, $\mathrm{NH}_{3}, \mathrm{NH}_{4} \mathrm{NO}_{3}$ and $\mathrm{NH}_{4} \mathrm{CH}_{3} \mathrm{COO}$, at $50^{\circ} \mathrm{C}$ for $72 \mathrm{~h}$. The wet gel was dried at $50^{\circ} \mathrm{C}$ until no shrinkage was observed. A wet gel without aging was also dried similarly. The dried gels were calcined at $800^{\circ} \mathrm{C}$ for $2 \mathrm{~h}$ at a heating rate of $100^{\circ} \mathrm{C} \mathrm{h}^{-1}$.

Silica gels without macropores for comparison were prepared from tetraethoxysilane (TEOS, Shin-Etsu Chemical). TEOS was mixed with an equi-volume of $1 \mathrm{~mol} \mathrm{dm}^{-3}$ nitric acid aqueous solution under vigorous stirring. The resultant homogeneous solution was sealed in a polystyrene container, and kept at $50^{\circ} \mathrm{C}$ for $20 \mathrm{~h}$. The obtained gel was aged, dried and calcined as performed for bimodal porous silica gels.

\subsection{Characterization}

Scanning electron microscope (SEM, SM200, Topcon) was employed for the observation of micrometer-scale morphology of the bimodal porous samples. Pore size distribution of the bimodal porous silica gel was measured with $\mathrm{Hg}$ porosimeter (POREMASTER-60, Quantachrome). A nitrogen adsorption isotherm was measured at $-196^{\circ} \mathrm{C}$ using OMNISORP 100CX (Beckman Coulter) after the sample had been degassed at $300^{\circ} \mathrm{C}$ for $1 \mathrm{~h}$. The specific surface area, $A$, and mesopore volume, $V_{\text {meso }}$, were calculated from the adsorption isotherm by the BET method and the amount of $\mathrm{N}_{2}$ adsorbed at $P / P_{0}>0.95$, respectively. Mesopore size distribution of pores smaller than $50 \mathrm{~nm}$ was calculated using the Dollimore-Heal method. A water-vapor adsorption isotherm was measured at $25^{\circ} \mathrm{C}$ on a BELSORP 28SA (Bel) after the sample had been degassed at $200^{\circ} \mathrm{C}$ for $3 \mathrm{~h}$.

Total pore volume, $V_{\mathrm{t}}$, including both mesopores and macropores was calculated from the difference in weight between the sample dried at $110^{\circ} \mathrm{C}$ and the sample containing water in its pores together with density of water. The water was introduced into pores by immersing the gel in water bath under reduced pressure. The porosity of the silica gel, $V_{\mathrm{f}}$, was calculated by the following equation assuming that the density of silica, $\rho$, is $2.20 \mathrm{~g} \mathrm{~cm}^{-3}$.

$$
V_{\mathrm{f}}=\frac{V_{\mathrm{t}}}{V_{\mathrm{t}}+\rho^{-1}}
$$

In order to evaluate advantages of the presence of macropores in humidity control, a gas diffusion coefficient in pores in a monolithic sample was obtained from the change in pressure with time in the adsorption of nitrogen at $-196^{\circ} \mathrm{C}$. After a sample with spherical-like shape had been degassed at $300^{\circ} \mathrm{C}$ for $1 \mathrm{~h}$, nitrogen gas was introduced at $-196^{\circ} \mathrm{C}$, and the pressure was measured as a function of time, $t$, until no change was detected for $200 \mathrm{~s}$. The amount of adsorbed nitrogen, $M_{\mathrm{t}}$, was calculated by the equation of state:

$$
M_{\mathrm{t}}=\frac{\left(P_{\mathrm{ini}}-P\right) V}{R T}
$$

where $P_{\text {ini }}$ and $V$ are the initial pressure at $t=0$ and the apparatus volume normalized to the manifold temperature, respectively. Because the gel volume was much smaller than $V, M_{\mathrm{t}}$ can be regarded as a total amount of nitrogen passing the outer surface of the monolithic gel.

For a sphere, the diffusion equation is described as $^{22)}$

$$
\frac{\partial C}{\partial t}=D\left(\frac{\partial^{2} C}{\partial r^{2}}+\frac{2}{r} \frac{\partial C}{\partial r}\right)
$$

where $C, r$ and $D$ were concentration, distance of diffusion and diffusion coefficient, respectively. Letting $u=C r$, Eq. (4) becomes

$$
\frac{\partial u}{\partial t}=D \frac{\partial^{2} u}{\partial r^{2}}
$$

For the $\left(t, M_{\mathrm{t}}\right)$ data set measured by adsorption, we can approximately apply the following initial and boundary conditions; $C=0$ at $0<r<a$ and $t=0$, and $C=C_{0}$ at $r=a$, where $C_{0}$ is concentration at the surface of the sphere and $a$ is the radius of the sphere. For the conditions, the total amount of diffusion substance entering the sphere can be given by ${ }^{22}$ )

$$
\frac{M_{\mathrm{t}}}{M_{\infty}}=1-\frac{6}{\pi^{2}} \sum_{n=1}^{\infty} \frac{1}{n^{2}} \exp \left(-\frac{D n^{2} \pi^{2} t}{a^{2}}\right)
$$

Equation (6) can be approximated at small $t$.

$$
\frac{M_{\mathrm{t}}}{M_{\infty}}=6\left(\frac{D}{\pi a^{2}}\right)^{1 / 2} \times t^{1 / 2}
$$

Although the validity of Eq. (7) is limited at small $t$ (typically at $\left.M_{\mathrm{t}} / M_{\infty}<0.2\right)$ because of rough approximation, we can calculate the diffusion coefficient from the slop of $M_{\mathrm{t}} / M_{\infty}$ vs. $t^{1 / 2}$ plot using Eq. (7).

\section{Results and discussion}

A monolithic white opaque gel, instead of transparent one, was obtained from the solution of water glass and HPAA. Figure 1 shows the SEM image of the silica gel sample aged in an ammonia aqueous solution (sample D in Table 1). As has

\begin{tabular}{|c|c|c|c|c|c|c|}
\hline & Solute in aging & $\mathrm{pH}^{\mathrm{a}}$ & $A / \mathrm{m}^{2} \mathrm{~g}^{-1}$ & $V_{m e s: \mathrm{s} / \mathrm{cm}^{3} \mathrm{~g}^{-1}}$ & $V .1 \mathrm{~cm}^{3} \mathrm{~g}^{-1}$ & $V \%$ \\
\hline Sample $A^{\mathrm{h}}$ & & & 512 & 0.330 & 1.73 & 79.2 \\
\hline Sample B & $\mathrm{NH}_{4} \mathrm{YO}_{3}$ & 5.4 & 517 & 0.479 & 165 & 78.4 \\
\hline Sample C. & $\mathrm{NH}_{4} \mathrm{CH}_{3} \mathrm{COO}$ & 6.9 & 306 & 0.862 & 2.50 & 84.6 \\
\hline Sample 1) & $\mathrm{NH}_{3}$ & 11.3 & 223 & 1.09 & 5.49 & 92.4 \\
\hline
\end{tabular}
been reported, ${ }^{20)}$ the silica gel has 3 -dimensionally intercon-

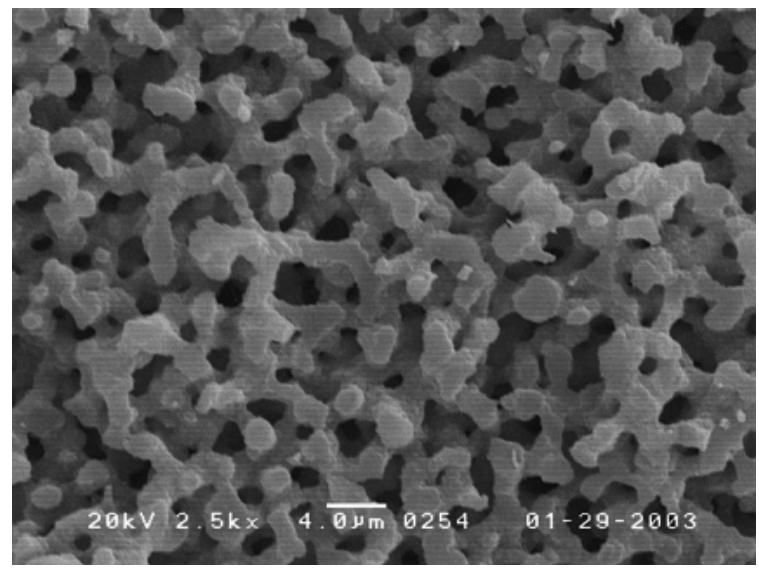

Fig. 1. SEM image of bimodal porous silica (Sample D in Table 1).

Table 1. Aging Conditions and Porous Properties of the Obtained Samples. Meaning of the Variables is Described in the Text 


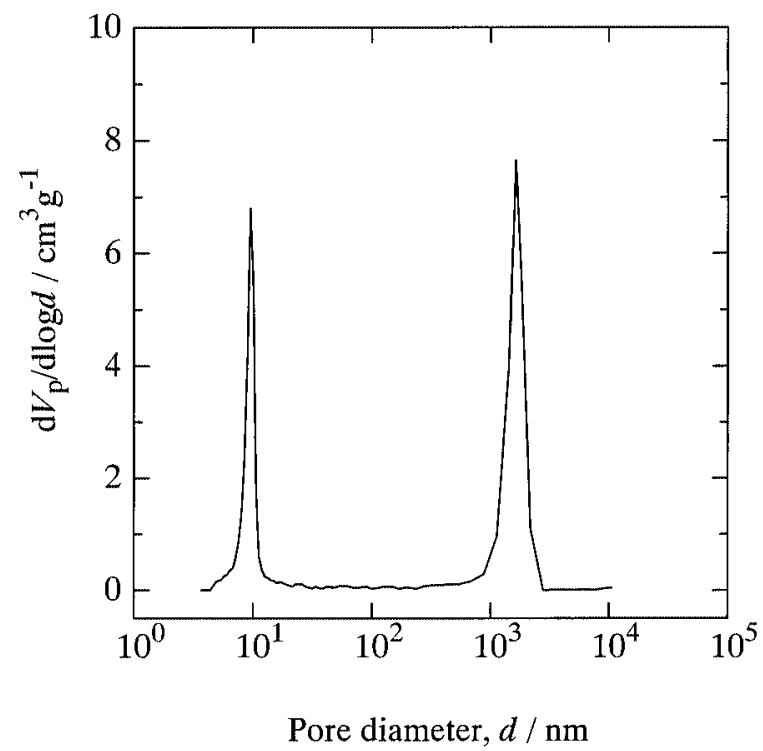

Fig. 2. Pore size distribution measured by mercury porosimetry for the silica shown in Fig. 1 (sample D in Table 1). $V_{\mathrm{p}}$, pore volume.

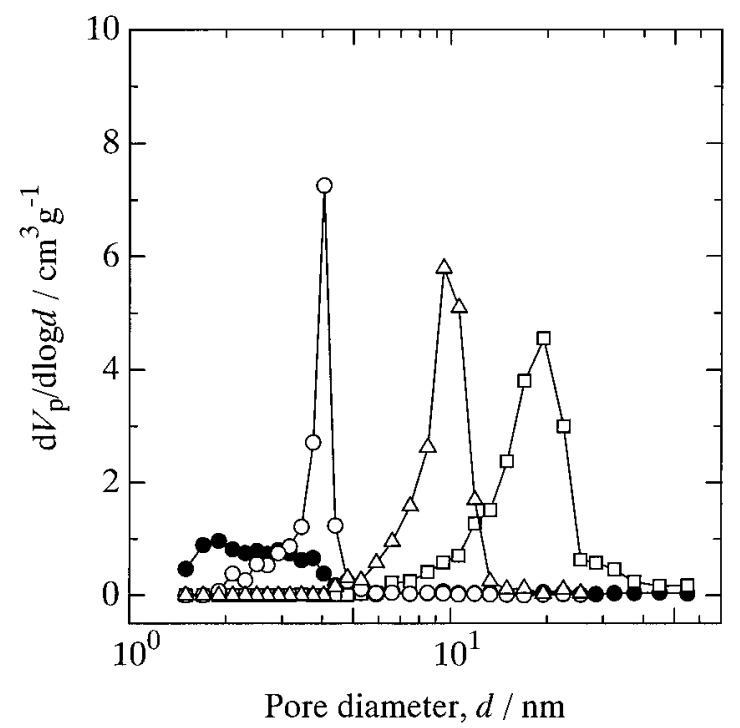

Fig. 3. Mesopore size distribution measured by $\mathrm{N}_{2}$ adsorption for the bimodal porous silica prepared with the different aging conditions. Closed circle, sample A; open circle, sample B; triangle, sample C; square, sample D.

nected macropores, whose size is controllable by changing the preparation composition. Figure 2 shows the pore size distribution measured by mercury porosimetry for the sample D. There are two sharp peaks at ca. $10 \mathrm{~nm}$ and $1.5 \mu \mathrm{m}$, corresponding to mesopores and macropores, respectively. The macropore size agrees with the pore size estimated from SEM in Fig. 1.

Table 1 and Fig. 3 show the porous properties and the mesopore size distribution measured by the nitrogen adsorption, respectively, for the samples treated with different aging conditions. By aging and with increasing $\mathrm{pH}$ of the aging solution, the peak in the distribution curve shifts to larger size, and both mesopore and total pore volumes increase. On the other hand, little difference in micrometer-scale morphology

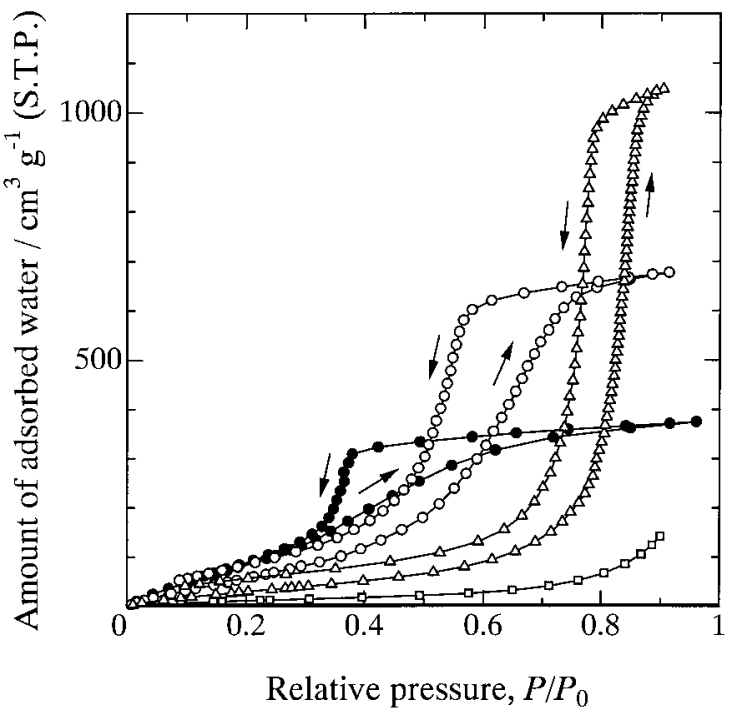

Fig. 4. Water-vapor adsorption isotherm of the bimodal porous silica samples. Symbols are the same as those in Fig. 3.

is observed with SEM among the samples (SEM images are not shown). The large total pore volume indicates that shrinkage of monolithic gel body during drying and calcination is small. The solubility of silica increases rapidly with the increase in $\mathrm{pH}$ of solution. ${ }^{23)}$ The difference in the pore structures by the aging $\mathrm{pH}$ is attributed to the different degree in the progress of Ostward ripening; silica particles can grow to larger size at higher $\mathrm{pH}$ through dissolution and reprecipitation. ${ }^{12)}$ In drying, the capillary force arises in the pores. Magnitude of the capillary force, $\Delta F$, is expressed as

$$
\Delta F=\frac{2 \gamma \cos \theta}{r_{\mathrm{p}}}
$$

Large silica particles formed by Ostward ripening would prevent shrinkage during drying because of high strength. In addition, the capillary force is inversely proportional to the pore radius. The sample with large mesopores shrinks less than that with small ones because of small capillary force. Thus, the sample aged under higher $\mathrm{pH}$ conditions prevents the shrinkage during drying, and has large size and volume of mesopores.

Figure 4 shows the water-vapor adsorption isotherm of the bimodal porous silica samples listed in Table 1. The amount of adsorbed water increases with increasing the relative pressure for all the samples, and a large increase accompanied with hysteresis is observed at the higher-pressure region for the samples A, B and C. This large increase is attributable to the capillary condensation of water vapor in mesopores, because its relative pressure roughly agrees with that inducing the capillary condensation estimated from mesopore size in Table 1 using Eq. (1) for these samples. Furthermore, it is recognized that the total adsorbed amount of water (Table 2, values in parentheses of column 5) agrees with the mesopore volume (Table 1) for these samples. Although little amount of water vapor was adsorbed on the sample with the largest mesopores (sample D) at $P / P_{0}<0.9$, capillary condensation of water vapor would occur at $P / P_{0}>0.9$ because of its large mesopores.

Incidentally, a hysteresis like those observed in Fig. 4 is commonly observed in a nitrogen adsorption isotherm of sol-gel-derived silica gels ${ }^{23)}{ }^{24)}$ and aggregates of fine crystal- 
Table 2. Water-Vapor Adsorption Characteristics of the Obtained Samples

\begin{tabular}{|c|c|c|c|c|}
\hline & $d / \mathrm{nm}^{n}$ & $P P_{0}{ }^{\mathrm{b}}$ & Water $/ \mathrm{cm}^{3} \mathrm{~g}^{-1 \mathrm{c}}$ & Water/g g-silizal ${ }^{-1 \mathrm{~d}}$ \\
\hline Sample A & 2.6 & $0.30-0.70$ & 210 & $0.16(0.29)$ \\
\hline Sample B & 3.7 & $0.40-0.80$ & 520 & $0.39(0.51)$ \\
\hline Sample C & 11.3 & $0.60-0.90$ & 950 & $0.71(0.79)$ \\
\hline
\end{tabular}

${ }^{a}$ Mesopore diameter calculated by $d=4 V_{\text {inew/ } / A \text {. }}$.

${ }^{\text {D }}$ Relative pressure at which hysteresis is observed.

${ }^{c}$ Difference in the amount of adsorbed water vapor between the both ends of hysteresis loop.

"Humidity control capacity when the humidity changes between the range in $P / P_{0}$. The values in the parentheses are the total amount of adsorbed water.

lites, ${ }^{25), 26)}$ when they have mesopores in which capillary condensation occurs. Among explanations of the reason of hysteresis, that based on the different menisci-growing processes between adsorption and desorption in so-called inkbottle pores has been widely accepted for these materials. ${ }^{8)}{ }^{23)}$ The origin of the hysteresis observed in the present water-vapor adsorption isotherm would be attributed to the presence of inkbottle pores, too. The presence of hysteresis controlled in an appropriate pressure range is convenient for humidity control as described in the following.

We summarize the relative pressure at which hysteresis is observed, and the difference in the amount of adsorbed water between the both ends of the hysteresis loop in Table 2 . When humidity changes between the lower and higher ends of hysteresis, each sample shows adsorption-desorption cycle with the adsorption capacity, as summarized in Table 2, which suppresses the change width of humidity. For example, sample B adsorbs $520 \mathrm{~cm}^{3} \mathrm{~g}^{-1}$ of water vapor when humidity increases from 40 to $80 \%$. This corresponds to ca. $0.4 \mathrm{~g}$ of water per $1 \mathrm{~g}$ of the sample, and such adsorption can suppress the humidity change. Humidity control between the range is quite important to serve comfortable room environment to human being. On the other hand, the sample $\mathrm{A}$ is suitable for preventing unusual dry-air, and the sample $\mathrm{C}$ is suitable for preventing dew condensation at high humidity, because the former releases adsorbed water at low humidity, $<40 \%$, and the latter adsorbs water vapor at high humidity, $>80 \%$. The water-vapor adsorption capacity of sample $\mathrm{C}$ exceeds $0.7 \mathrm{~g}$ per gram of silica. These equilibrium adsorption amounts of water in adsorption-release cycle are higher than the other porous materials in literature. ${ }^{1,7)}$ Combination of these monolithic silica gel samples with different mesopore sizes corresponding to the respective climates will provide superior humidity-control ability.

Table 3 lists the samples used in the evaluation of diffusion rate of nitrogen gas in pores. Samples 1 and 2 have bimodal pore structures, and those 3, 4, and 5 have only mesopores with different sizes. Sample 6 is powdered sample 5, and packed bed is regarded as a monolithic sphere. That is, the inter grains in packed powders are expected to work as macropores. From the change in pressure with time in nitrogen adsorption at $-196^{\circ} \mathrm{C}$, we can calculate $M_{\mathrm{t}}$ using Eq. (3). Figure 5 plots the typical change in $M_{\mathrm{t}} / M_{\infty}$ with root of time. We can calculate the diffusion coefficient of nitrogen gas in pores at $-196^{\circ} \mathrm{C}$ from the slope of the fitting line at the initial stage using Eq. (7). Here, the radius of the spherical sample was calculated according to

$$
a=\left(\frac{3}{4 \pi}\left(V_{\mathrm{t}}+\frac{1}{\rho}\right) w\right)^{1 / 3}
$$

where $w$ is weight of the sample. For sample 6, an inverse of
Table 3. Porous Properties of the Silica Samples Used in the Test of Gas Diffusion

\begin{tabular}{|c|c|c|c|c|c|c|}
\hline & Form & $A / \mathrm{m}^{2} \mathrm{~g}^{-1}$ & $V_{\text {maxise }} \mathrm{cm}^{3} \mathrm{y}^{-1}$ & $l / / \mathrm{cm}^{3} \mathrm{~g}^{-1}$ & $1 / \%$ & $d / \mathrm{nm}$ \\
\hline Sample I ${ }^{\mathrm{a}}$ & Monolith & 377 & 0.160 & 1.96 & 81.1 & $6500^{d}\left(1.7^{c}\right)$ \\
\hline Sample $2{ }^{b}$ & Monolith & 512 & 0.330 & 1.73 & 79.2 & $1500^{d}\left(2.7^{\circ}\right)$ \\
\hline Sample 3 & Monolith & 211 & 0.897 & 0.951 & 67.6 & $170^{\circ}$ \\
\hline Sample 4 & Monolith & 308 & 0.809 & 0.769 & 64.6 & $10.5^{\circ}$ \\
\hline Sample 5 & Monolith & 395 & 0.207 & 0.218 & 34.2 & $2.1^{\circ}$ \\
\hline Sample $6^{\mathrm{c}}$ & Powder & 395 & 0.207 & 0.218 & 34.2 & $2.1^{\mathrm{c}}$ \\
\hline $\begin{array}{l}\text { "Prepared } \\
\text { preparation } \\
\text { "Sample A ir } \\
\text { "Powdered s } \\
\text { "Macropore } \\
\text { "Mesopore s }\end{array}$ & $\begin{array}{l}\text { ing } 60 \mathrm{~g} \\
\text { nditions ar } \\
\text { Table } 1 \text {. } \\
\text { nple } 5 \text {. } \\
\text { ze obtaine } \\
\text { e calculate }\end{array}$ & om & mages. & $0 \mathrm{~g}$ in & co & itions. Oth \\
\hline
\end{tabular}

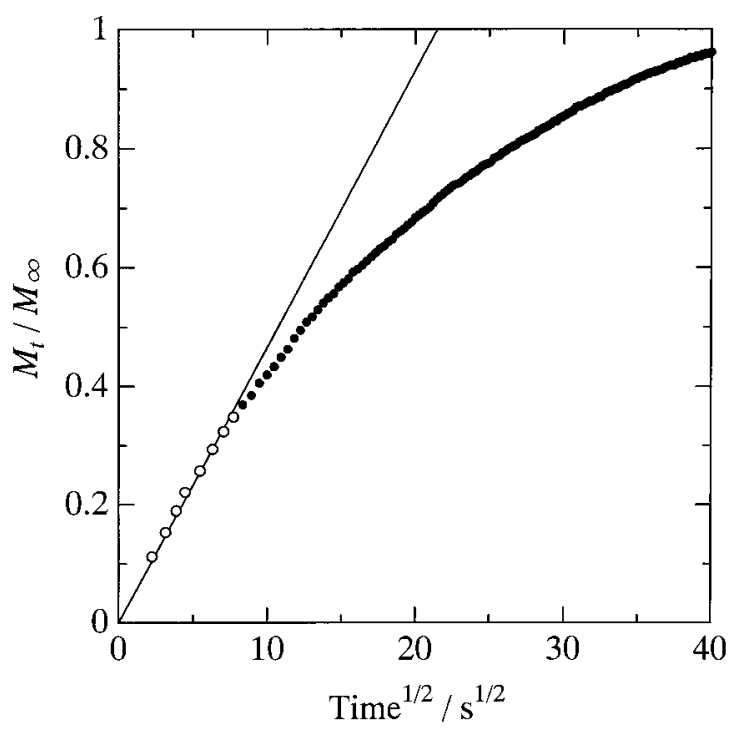

Fig. 5. $\quad M_{\mathrm{t}} / M_{\infty}-t^{1 / 2}$ plot of Sample 5 in Table 3. Both open and closed circles are the measured data points, while the open ones are used for fitting to Eq. (7). The solid line is obtained by the fitting.

packing density was used instead of $\left(V_{\mathrm{t}}+1 / \rho\right)$.

Figure 6 shows the relation between diffusion coefficient and pore diameter. In the monolithic samples, the diffusion coefficient increases with increasing the pore diameter at $<50$ $\mathrm{nm}$, and the change becomes very small at $>50 \mathrm{~nm}$. The diffusion coefficient for the packed-powder sample is almost the same as those for the bimodal porous samples. This agreement in the diffusion coefficient irrespective of pore size at $>50 \mathrm{~nm}$ indicates that diffusion is governed by the molecular diffusion for these samples. On the other hand, the gas diffusion in pores is governed by the Knudsen diffusion when the mean free path of gas is larger than the pore size ${ }^{27)}$

$$
D=\frac{2}{3} r_{\mathrm{p}}\left(\frac{8 R T}{\pi M}\right)^{1 / 2}
$$

where $M$ is molecular weight of gas molecules. The theoretical diffusion coefficient in mesopores is a function of molecular weight of gas and pore size. The measured $D$ values for samples 3, 4, and 5 are ca. 100 times smaller than the theoretical prediction using Eq. (10). This difference between experimental and theoretical values would be attributed to the porosity, tortuosity, ${ }^{27)}$ decrease in effective pore size due to 


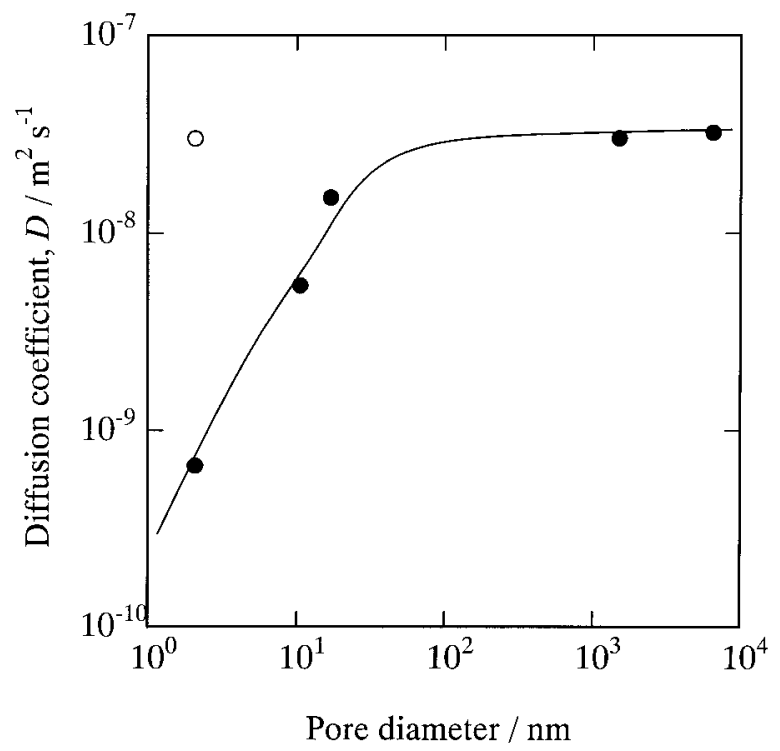

Fig. 6. Diffusion coefficient of nitrogen in the porous silica gel samples at $-196^{\circ} \mathrm{C}$. Closed circles, monolithic samples; open circle, powder sample; solid line, guides for the eye.

the formation of surface adsorption layer and the effect of adsorption rate. It is considered, therefore, that the Knudsen diffusion is predominant at $<50 \mathrm{~nm}$ in pore diameter, and that transition to the molecular diffusion occurs over $50 \mathrm{~nm}$. Thus, macropores in the monolithic bimodal porous samples work as pathways for the rapid gas diffusion like inter-grain spaces in the packed-powder sample. Here, it should be emphasized that the mean free path of gas at $-196^{\circ} \mathrm{C}$ was much shorter than that at room temperature. The effectiveness of the presence of macropores for rapid gas diffusion will become more significant at room temperature. This would be proved in our future work.

Thus, the monolithic bimodal porous silica has two advantages in the humidity control application. One is its high potential for equilibrium adsorption amount of water vapor. We can design the control range of humidity by changing mesopore size. The other is rapid response for the change in humidity by the rapid diffusion due to the presence of macropores. Because of low production cost, the bimodal porous silica prepared from water glass would be applicable for building materials as an advanced humidity-controllable material.

\section{Conclusion}

Bimodal porous silica gel with both controlled macropores and mesopores was prepared from water glass in the presence of poly (acrylic acid). In the silica gel, mesopore size successively increased with increasing the $\mathrm{pH}$ in aging without affecting macroporous morphology. The silica gel has high potential as a humidity control material; it has high adsorption capacity of water vapor and macropores effectively work as a pathway for rapid diffusion of gas molecules. The humidity, at which adsorption-release of water occurs reversibly over the silica, is controllable by changing mesopore size. It agrees well with the prediction using the Kelvin equation.
Acknowledgement The authors thank Messrs Hiroshi Nagai and Hitoshi Itoh, Ebara Research Co., Ltd., for the measurement of water-vapor adsorption isotherm.

\section{References}

1) Yoshida, S. and Matsushita, R., Japanease Patent, P2000282593A.

2) Maeda, M., Wang, X., Tomura, S., Ohashi, F., Suzuki, M. and Okada, K., J. Ceram. Soc. Japan, Vol. 106, pp. 428-431 (1998).

3) Ohashi, F., Maeda, M., Suzuki, M., Tomura, S., Okazaki, M. and Toriyama, K., J. Ceram. Soc. Japan, Vol. 107, pp. 844-849 (1999).

4) Caturla, F., Molina-Sabio, M. and Rodriguez-Reinoso, F., Appl. Clay Sci., Vol. 15, pp. 367-380 (1999).

5) Ohashi, F., Maeda, M., Inukai, K., Suzuki, M. and Tomura, S., J. Mater. Sci., Vol. 34, pp. 1341-1346 (1999).

6) Maeda, M., Tomura, S., Ohashi, F., Suzuki, M. and Okada, K., J. Ceram. Soc. Japan, Vol. 108, pp. 1024-1029 (2000).

7) Maeda, M., Suzuki, S., Tomura, S., Ohashi, F., Kimura, T. and Okada, K., J. Ceram. Soc. Japan, Vol. 110, pp. 121-125 (2002).

8) Kondo, S., Ishikawa, T. and Abe, I., "Kyuchaku-no-Kagaku," 2nd ed., Maruzen, Tokyo (2001) pp. 52-57 [in Japanese].

9) Nakanishi, K. and Soga, N., J. Am. Ceram. Soc., Vol. 74, pp. 2518-2530 (1991).

10) Nakanishi, K. and Soga, N., J. Non-Cryst. Solids., Vol. 139, pp. 1-13 (1992).

11) Nakanishi, K., J. Porous Mater., Vol. 4, pp. 67-112 (1997).

12) Takahashi, R., Nakanishi, K. and Soga, N., Faraday Discuss., Vol. 101, pp. 249-263 (1995).

13) Nakanishi, K., Takahashi, R., Nagakane, T., Kitayama, K., Koheya, N., Shikata, H. and Soga, N., J. Sol-Gel Sci. Technol., Vol. 17, pp. 191-210 (2000).

14) Minakuchi, H., Nakanishi, K., Soga, N., Ishizuka, N. and Tanaka, N., Anal. Chem., Vol. 68, pp. 3498-3501 (1996).

15) Minakuchi, H., Nakanishi, K., Soga, N., Ishizuka, N. and Tanaka, N., J. Chromatogr. A, Vol. 797, pp. 121-131 (1998).

16) Nakamura, N., Takahashi, R., Sato, S., Sodesawa, T. and Yoshida, S., Phys. Chem. Chem. Phys., Vol. 2, pp. 4983-4990 (2000).

17) Takahashi, R., Sato, S., Sodesawa, T. and Yabuki, M., J. Catal., Vol. 200, pp. 197-202 (2001).

18) Yabuki, M., Takahashi, R., Sato, S., Sodesawa, T. and Ogura, K., Phys. Chem. Chem. Phys., Vol. 4, pp. 4830-4837 (2002).

19) Takahashi, R., Sato, S., Sodesawa, T., Haga, A. and Nishino, H., J. Ceram. Soc. Japan, Vol. 112, pp. 99-103 (2004).

20) Takahashi, R., Sato, S., Sodesawa, T. and Yachi, A., J. Ceram. Soc. Japan, Vol. 109, pp. 577-579 (2001).

21) Nishino, H., Takahashi, R., Sato, S. and Sodesawa, T., J. NonCryst. Solids., Vol. 333, pp. 284-290 (2004).

22) Crank, J., "The Mathematics of Diffusion," 2nd ed., Oxford University Press, Oxford (1975) Ch. 4.

23) Brinker, C. and Scherer, J., "Sol-Gel Science, The Physics and Chemistry of Sol-gel Processing," Academic Press, New York (1990) Chapters 3 and 9.

24) Takahashi, R., Sato, S., Sodesawa, T., Kawakita, M. and Ogura, K., J. Phys. Chem. B, Vol. 104, pp. 12184-12191 (2000).

25) Takahashi, R., Takenaka, S., Sato, S., Sodesawa, T., Ogura, K. and Nakanishi, K., J. Chem. Soc., Faraday Trans., Vol. 94, pp. 3161-3168 (1998).

26) Takenaka, S., Takahashi, R., Sato, S., Sodesawa, T., Matsumoto, F. and Yoshida, S., Microporous Mesoporous Mater., Vol. 59, pp. 123-131 (2003).

27) Smith, J. M., "Chemical Engineering Kinetics, 3rd ed.," McGraw-Hill Book Co., New York (1981) pp. 452-470. 